\title{
Hedging the Price Risk Inherent in Revenue Protection Insurance
}

\author{
Sweta Tiwari ${ }^{1} \odot$, Keith H. Coble ${ }^{2 \star}$, Barry J. Barnett ${ }^{3}$ and Ardian Harri ${ }^{2}$ \\ ${ }^{1}$ Geospatial Institute, Saint Louis University, St. Louis, MO, USA, ${ }^{2}$ Department of Agricultural Economics, Mississippi State \\ University, Mississippi State, USA and ${ }^{3}$ Department of Agricultural Economics, University of Kentucky, Lexington, KY, USA \\ ${ }^{\star}$ Corresponding author. E-mail: coble@agecon.msstate.edu
}

\begin{abstract}
Crop revenue insurance is unique, because it involves a guarantee subsuming yield risk and highly systematic price risk. This study examines whether crop insurers could use options instead of, or in addition to, assigning policies to the Commercial Funds of the USDA Federal Crop Insurance Corporation (FCIC) as per the Standard Reinsurance Agreement (SRA) to hedge the price risk of revenue insurance policies. The behavioral model examines the optimal hedge ratio for a crop insurer with a book of business consisting of corn Revenue Protection (RP) policies. Results show that a mix of put and call options can hedge the price risk of the RP policies. The higher optimal hedge ratios of call options as compared to put options imply that the risk of increased liability due to upside price risk can be hedged using options better than downside price risk. This study also analyzed the combination of options with the SRA at 35, 50, and 75\% retention levels. The zero optimal hedge ratios at each retention level and the negative correlation between RP indemnities and the option returns when the crop insurer mixed options and SRA suggest that the purchasing of options provides no additional risk protection to crop insurers beyond what is provided by the SRA despite retention limits.
\end{abstract}

Keywords: crop revenue insurance policies; optimal Hedge Ratio; options; reinsurance

JEL Classifications: Q18; Q13

\section{Introduction}

Revenue insurance is unique in that the guarantee subsumes a highly systematic price risk. Standard insurance logic is that systematic risks are not insurable. Crop revenue insurance indemnifies the deficit in the farmer's gross revenue resulting from either low yield, low price, or a combination of the two. If low prices trigger indemnities, the revenue insurance policy could indemnify almost all policyholders at the same time. Miranda and Glauber (1997) estimated that the ten largest crop insurers' insurance portfolio was 20 times riskier than the portfolio of the insurer's holding uncorrelated risks. This is important, because in a systematic loss event (such as price declines for a revenue insurance policy), the crop insurers may not have sufficient capital to meet their obligations to the insured. As the price risk in crop insurance is common to all insured revenue insurance policies for a crop with the same sales closing date, it has attributes that are often handled through future and option markets.

In the US crop insurance industry, the risk of crop insurance policies is typically reinsured by the USDA and private reinsurers. Given the price risk component of revenue insurance, this paper investigates the potential use of options along with the transfer of risk from crop insurers to the federal government to mitigate the price risk present in corn RP policies. Furthermore, if hedging

(c) The Author(s), 2021. Published by Cambridge University Press on behalf of the Southern Agricultural Economics Association. This is an Open Access article, distributed under the terms of the Creative Commons Attribution licence (http://creativecommons.org/licenses/by/4.0/), which permits unrestricted re-use, distribution, and reproduction in any medium, provided the original work is properly cited. 
using options mitigates the price risk inherent in holding corn RP policies, then what is the optimal hedge ratio?

Ultimately, in 2020, approximately $\$ 77$ Billion dollars of revenue liability is sold which reflects more than 70\% of all US crop insurance liabilities (RMA, 2021). Private reinsurance markets are generally loaded with brokerage fees and general expense loading. Conversely, the low transaction cost and efficiency of future markets are well known. Thus, it is possible that the use of futures and options would allow the USDA reinsurance to exclude the price risk it now subsumes. The potential for hedging by crop insurers through derivative instruments has been rarely examined. The notable exceptions include the works of Driedger et al., (2016). Driedger et al., (2016) examined the possibility of using the long futures and long call options to manage yield insurance losses on canola in Western Canada. They found that these hedge positions increased losses as compared to unhedged positions when the future price declined. To the best our knowledge, this work and Tiwari (2017) are the first to address the price risk in revenue insurance specifically. We do so by building a simulation model for the corn revenue book of business in the US.

The simulation model is based on the county yield data for corn from USDA's National Agricultural Statistics Service (NASS) and the price data from the Commodity Research Bureau's (CRB) the national-level daily corn future prices from 1985 to 2018 . We find that call options can hedge the upside price risk of RP when yield declines. Put options, however, are not effective in hedging the downside price risk due to the negative price yield correlation in the Midwest. These findings suggest that USDA could protect crop insurers only against the downside price risk, while the option market could be used to hedge the upside price risk. This leads to the possibility of a restructured SRA that lets the private sector to handle the price risk of revenue insurance. This study also analyzed the combination of options with the SRA at 35, 50, and 75\% retention levels. We find that the optimal hedge ratio is zero and option returns are negatively correlated with RP indemnities when the crop insurer mixed options and SRA to hedge the price risk, thereby indicating that USDA SRA is a clear substitute for options. In other words, the purchasing of options provides no additional risk protection to crop insurers beyond what is provided by the SRA despite retention limits.

The remainder of this paper is organized as follows. First, we present an overview of revenue insurance as operated in the United States and then provide a literature review. Next, the behavioral model frames the crop insurer's planting-time optimization model to examine the optimal hedge ratio. This is followed by a discussion of the data and methods used in the analysis. We then report our findings and answer whether a crop insurer could use options alone or in combination with the SRA, to hedge the price risk inherent in revenue insurance policies.

\section{Overview of Revenue Insurance}

The revenue guarantee for crop revenue insurance is calculated based on commodity future prices and actual production history. Two versions of crop revenue insurance are offered in the US, namely, Revenue Protection (RP) and Revenue Protection with Harvest Price Exclusion (RP-HPE). Both crop revenue insurance policies indemnify revenue loss when both prices and yields decline at the same time based on a pre-season projected future price and actual production history (APH). In brief, a crop insurer faces a risk of losses due to a price decline (downside price risk) and a risk of increased liability when price increases (upside price risk) and yields decline. This is particularly relevant for crops and regions such as corn in the Corn Belt where good or bad crop yields move corn prices in the opposite direction (a negative correlation between yield and price) (Goodwin \& Hungerford 2015; Ramsey et al. 2019).

If only the price of the commodity declines and the actual yield is equal to or greater than APH, then both RP and RP-HPE provide a guarantee based on pre-season projected future price. When the harvest price of a crop declines relative to the projected price, put option contracts are 
expected to reduce the price risk of the insurer. In other words, a crop insurer could buy put option contracts to hedge both RP and RP-HPE liabilities.

In addition, when harvest price increases, the revenue guarantee of RP policies increases and might result in indemnity payments when the yield declines in a magnitude that is sufficient to trigger a payment. Thus, RP indemnifies yield losses at the increased harvest time price when yields decline and price increases. However, the revenue guarantee of RP-HPE ${ }^{1}$ policies is solely determined based on pre-season projected prices and does not increase with the harvest price. To hedge against a higher harvest price relative to the projected price, the insurer may choose to buy call options. Call option contracts provide a hedge against the RP liability when yield declines and price increases.

In the context of the US crop insurance industry, crop insurers can transfer their risk to the Federal Crop Insurance Corporation (FCIC) and/or private reinsurers. The crop insurers can transfer a certain percentage of net losses to FCIC by allocating their policies into two different risk-sharing funds, namely, the Assigned Risk Fund and the Commercial Fund, in exchange for the same percentage of premiums (SRA, 2015). By assigning policies to the Assigned Risk Fund, crop insurers can retain a $20 \%$ interest in premium and associated aggregate net losses in each state. The remaining $80 \%$ are ceded to FCIC (SRA, 2015). In the Commercial Fund case, crop insurers can retain at least $35 \%$ interest in premium and associated net losses, with the remainder being ceded to FCIC (SRA, 2015).

Interestingly, crop insurers often chose to retain more than the minimum premium and associated loss risk (Coble et al., 2007). In most states, the retention rate is $100 \%$ in the commercial fund, as this fund has more profit potential compared to the assigned risk fund (Collins, 2011). These firms then turn to private reinsurers that provide additional risk protection at market rates. Not only crop insurers but also other insurers, such as life and non-life insurers, reinsure only parts of their liabilities in exchange for their premium income to reinsurers. The International Association of Insurance Supervisors (IAIS) reported that in 2010, non-life insurers ceded less than $10 \%$, and life insurers ceded around $2 \%$ of their premium income to private reinsurers (IAIS, 2012). Reinsurers are liable to cover insurers' losses as per the reinsurance contracts. To meet future obligations, reinsurers employ risk management techniques, such as retrocession and investment in capital markets (IAIS, 2019). Equity and debt securities cumulatively accounted for $77.5 \%$ of total investment in the reinsurance industry (IAIS, 2019).

The reinsurance contracts are designed using the same insurance principles, that address only diversifiable risk, as insurers (ESRB, 2015). Moreover, it will be costly for reinsurers to hold sufficient reserves to cover the huge losses resulting from widespread catastrophic events, (e.g., drought), thereby rendering crop reinsurance excessively expensive (Miranda \& Glauber, 1997). Therefore, private reinsurers, such as small insurers, are unwilling or unable to offer policies that compensate for systematic risk. To address this, many insurers, such as life insurers and property and casualty insurers, now hedge some of their systematic loss exposure using options or other financial derivatives. The National Association of Insurance Commissioners (NAIC) reported that in 2017, the number of US insurers having derivative exposure was 311 . Out of 311 , the life insurers accounted for $70 \%$ and the property and casualty insurers accounted for approximately 25\% (NAIC, 2018). The insurers participating in the derivative markets are using the derivative tools for three primary purposes: a) hedging, b) replicating assets, and c) generating income (NAIC, 2018; Wong, 2018). In terms of hedging, these insurers are typically hedging the interest rate risk, equity risk, and foreign exchange risk through the market (Wong, 2018). In 2017, swaps were reported as the largest derivative instrument used by insurers accounting for $48 \%$ of total notional value, followed by options (39\%), futures (5\%), and forwards (3\%) (NAIC, 2018).

\footnotetext{
${ }^{1}$ For more practical application, the current study is only focused on RP policies are typically not purchased in practice and also examines the hedging strategy in which put, and call options are combined to hedge the price risk of RP.
} 
However, there is no evidence regarding whether crop insurers are hedging the systematic risk of revenue insurance policies using derivatives. Furthermore, in the context of the crop insurance industry, many researchers have focused their studies on how crop insurers manage their risk through reinsurance, especially through the SRA (Porth et al., 2013; Shields, 2010; Vedenov et al., 2004).

\section{Literature Review}

This present study is particularly interested in the risks confronted by US crop insurers selling revenue insurance policies, given the increasing demand for crop revenue insurance in recent years. In the US, the revenue-based policies accounted for $69.3 \%$ of total liabilities in the federal crop insurance program in the year 2017 (Rosa, 2018). Shaik et al. (2008) found that farmers, who perceived high yield risk, had a greater tendency to purchase revenue insurance rather than yield insurance, as the revenue insurance provides upside price risk coverage. In other words, the RP policies would provide more per unit indemnities than yield insurance if prices raised before harvest (Shaik et al., 2008). Even though revenue insurance provides greater protection than yield insurance, the premiums of revenue policies are heavily subsidized by the federal government ranging from $100 \%$ for catastrophic coverage to $38 \%$ for $85 \%$ coverage level (Lusk, 2017) which had significantly increased the demand for revenue insurance (O'Donoghue, 2014).

In the US, Risk Management Agency (RMA) of the United States Department of Agriculture (USDA) designs, rates, and underwrites the revenue insurance. However, the policies are delivered by the private firms who share in the risk exposure of the policies that they sell (Tiwari, 2017). The crop insurers can limit their risk exposure through reinsurance. Duncan and Myers (2000) and Porth (2015) argued that reinsurance helps crop insurer to not only diversify their risk, but also stabilize their reserves. Miranda and Glauber (1997) further argued that private crop insurance markets could fail without affordable reinsurance, as the private crop insurer would not be able to pool the systemic risk across farms. Private crop insurers can purchase reinsurance for their portfolio from the government agency or private reinsurance companies. However, crop insurers cannot transfer all their systematic risks through reinsurance contracts. Private reinsurance companies have devised various contractual provisions, such as coinsurance arrangement, the deductible arrangement, explicit contingent pricing schemes, and experience ratings to deal with incentive problems (Niehaus \& Mann, 1992). When more risk is transferred to a reinsurer, the less incentive the insurance company has to select low-risk policyholders, to reduce claim costs, and to classify losses as being covered under the reinsurance contract (Niehaus \& Mann, 1992). Furthermore, the government agency such as RMA protects the crop insurer in exchange for a certain percent interest in premium. However, motivated by earning a profit, the crop insurers were found to retain less premium to reinsurance funds in recent years (Bulut et al., 2011).

Having exposure to price risks that cannot be pooled across the farms, crop insurers need alternative ways to hedge their price risk. One of the possible ways to hedge systematic risk is to use option or future instruments. As compared to reinsurance, the option or future markets can neutralize the effects of price risk more efficiently by transferring the risk from hedgers to speculators (Carlton, 1984). Not only do option or future markets shift price risks, but also correct market inefficiencies in commodity markets through the provision of intertemporal prices, price discovery, and disseminating information (Carlton, 1984; Cater, 2003). Despite both the future and option contracts hedge the systematic risk, a buyer of either a put or call faces limited risks, does not have to deposit margin calls, and can exercise multiple hedging strategies such as taking either short or long put and call positions (Cater, 2003). As either a floor or a ceiling price can be established with options, the option contracts are more like traditional price insurance than futures (Cater, 2003). An option is a standardized contract providing its owner the right to sell/buy and its writer the obligation to buy/sell a future contract on a particular commodity at a specified 
price (strike price), with the right lasting until the maturity date of the contract (Kolb \& Overdahl, 2003). The buyer will exercise put options based on the assumptions that the market price of the underlying future contract falls below the strike price protecting against a price decrease (Kolb \& Overdahl, 2003). On the contrary, the investor may choose to buy call options when the buyer believes that the price of the underlying future contract is going to rise above the strike price ensuring a certain return from a price increase (Kolb \& Overdahl, 2003). Buyers of both the put and call options can choose not to exercise their rights depending on the hedging and arbitrage opportunities available to them (Kolb \& Overdahl, 2003).

Cox and Schwebach (1992) used the Black-Scholes (BS) option pricing model to examine the possibility of using insurance futures (i.e., a European call option on insurance futures and put options) as a tool for hedging the insurer's business risk. Ye et al. (2017) developed the improved BS model for the calculation of crop price insurance premiums and suggested the possibility of hedging underwriting risks of crop insurance firms through the future market. Using probit regression models, Takao and Lantara (2010) examined the determinants of the use of derivatives by life insurance and non-life insurance companies in Japan. They found that decision to use derivatives by insurance companies was positively related to firm size, leverage, and proportion of asset invested in stock, while negatively related to asset-liability mismatch.

In the context of the crop insurance industry, numerous studies had analyzed the issue of farmers hedging the uninsured price risk associated with revenue or yield insurance (Coble et al. 2000; Coble et al. 2004; Jacobs et al. 2018; Mahul, 2003; Mahul \& Vermersch, 2000; Walters \& Preston 2018; Wang et al., 2004,). Most of these studies had examined the relationship between risk management tools (such as futures and options) and crop insurance and discovered that revenue insurance availability lowers the demand for hedging (Coble et al. 2000; Coble et al. 2004; Walters \& Preston 2018). One consistent thread found in the literature evaluating crop producer hedging decision is to provide hedge ratios using different econometric models, such as minimum-variance hedge ratio, regression, and expected utility framework. Sévi (2004) used the minimum variance method to investigate the impact of production cost variability on hedging decisions. Caldarelli (2010) compared the effectiveness of the four positions (unhedged, naive and minimum variance hedge, and dynamic hedge) in minimizing price risk and optimizing expected return for the soybean product. Witt et al. (1987) analyzed the differences among the three models (i.e., price difference model, percent change model, and price-level model) used to estimate hedge ratio using barely and sorghum cash and corn future prices. He found that price-level regression had accurately estimated optimal hedge ratios as compared to the other two models. Myers and Thompson (1989) detected that simple regression using price levels or returns led to errors in optimal hedge ratio estimation. Wang et al. (2004), Coble et al. (2004), Mahul (2003), Coble et al. (2000), and many more examined the crop producer hedging decision in an expected utility framework. These authors concluded that crop producers were risk averse, and the use of any risk management tools such as futures, options, and crop insurance would improve the producer's welfare.

\section{The Behavioral Model}

An optimal hedge ratio is used to evaluate the potential use of options in hedging the RP policies' price risk. Based on risk preferences, a decision maker will hedge at the ratio that maximizes expected utility. To calculate the optimal hedge ratio of crop insurers holding revenue insurance policies, we modify the Coble et al., 2000 behavioral model to examine an insured crop producer's planting-time hedging optimization.

A crop insurer is assumed to hedge against corn RP indemnity risk after the pre-season sales period is completed in the current analysis. Then, net returns from insurance and options are used to determine the end of period wealth when the insurer (1) hedges using options exclusively and (2) assigns policies to the Commercial Fund and hedges with options combinedly. Finally, the 
end-of-period wealth determines the insurer's expected utility and certainty equivalent, which estimates the optimal hedge ratio. We assume von Neumann-Morgenstern axioms of behavior as did Coble, Dismukes, and Glauber (2007). This contrasts with seminal insurance literature, such as Arrow (1970), which assumes that the insurer is risk-neutral. However, there is strong evidence of risk-averse behavior among insurers by the presence of the world reinsurance market. BusinessWire (2020) reports a world reinsurance volume of over $\$ 400$ billion in 2019 . The insurer's utility function is also assumed to exhibit moderate constant relative risk aversion (CRRA). ${ }^{2}$ We model the distribution of the total RMA insurance book of business, which we assume to reflect the book of a representative private crop insurer.

\subsection{Book of Business}

Equation (1) defines the net return, $N R$, on the crop insurance company's book of business, $B$

$$
N R_{B}=\sum_{i=1}^{n}\left[P_{i j}-\operatorname{Max}\left\{0,\left\{R G_{i j}-f_{1} y_{i}\right\}\right\}\right]
$$

where $N R_{B}$ represents that the net return calculates as the difference between the total indemnities paid by the RP policies out of the total premium received. $P_{i j}$ is the premium paid by farm $i$ for coverage level $j, n$ is the number of farms, $R G_{i j}$ is the revenue guarantee for farm $i$ for coverage level $j, f_{1}$ is the future price at harvest, and $y_{i}$ is the actual yield for farm $i$. The revenue guarantee for RP, $R G_{i j}$, is defined in equation (2) as

$$
R G_{i j}=C_{i j} \times y_{g i} \times \operatorname{Max}\left(f_{0}, f_{1}\right) .
$$

The revenue guarantee for RP $\left(R G_{i j}\right)$ is calculated as the product of the higher of projected price, $f_{0}$, or harvest price, $f_{1}$, approved yield, $y_{g i}$, for farm $i$, and chosen coverage level, $C_{i j}$. The approved yield, $y_{g}$, is an average of a crop producer's yield over a minimum of 4 years and a maximum of 10 years. Projected and harvest prices for a corn RP policy are determined by calculating the monthly average of the December future contract's daily prices during February and October, respectively. ${ }^{3}$ An indemnity, $I_{i j}$, is paid when the revenue guarantee exceeds the actual revenue:

$$
\left\{\begin{array}{l}
I_{i j}>0 \text { if } C_{i j} \operatorname{Max}\left(f_{0}, f_{1}\right) y_{g i}>f_{1} y_{i} \\
I_{i j}=0 \text { if } C_{i j} \operatorname{Max}\left(f_{0}, f_{1}\right) y_{g i} \leq f_{1} y_{i}
\end{array}\right\} .
$$

We first discuss when a crop insurer transfers the price risks of RP policies using only option contracts. Next, we discuss the scenario where the crop insurer uses both options and reinsurance through the SRA.

\subsection{Hedging Through the Option Market}

This study assumes that the crop insurer will buy a mix of both put and call options to hedge the price risk of corn RP policies. For RP policies, the lower harvest price results in the indemnity payment based on the projected price even if the actual yield is higher than the APH yield. If prices do not decline, the RP policy effectively becomes a yield insurance policy providing a revenue guarantee at the harvest price. As RP protects both downside and upside price risks, this study assumes that a crop insurer offering RP policies buys a mix of put and call options at a strike equal to the projected price, $f_{0}$, and at a cost equal to the option premium. At the same strike price, both call and put options would be at-the-money simultaneously. Otherwise, when a crop insurer buys a put option in-the-money and when the strike price is greater than the projected price, a call

\footnotetext{
${ }^{2}$ This implies a relative risk aversion coefficient of two. A sensitivity analysis with different values of the relative risk aversion coefficient was conducted as well.

${ }^{3}$ The price determination period varies with regions. This study assumes that the price determination periods for all regions are the same as for the Midwest region.
} 
option with the same strike price will be out-of-the-money vice versa. At-the-money puts and calls conceptually reduce all price risk. However, out-of-the-money options would be cheaper, and hedgers might sometimes take that approach-less risk protection but at a lower fair price. The result is that the hedge ratios found in these results represent an upper bound on the hedge ratio.

The insurer offering corn RP policies will exercise either the put options when the harvest price of the December corn future contract falls below the projected price protecting against the price decrease or the call options when the harvest price of the corn December future contract rises above the projected price protecting against the increased liability that will trigger indemnity when yields decline in a sufficient magnitude. The net returns from put $(N P)$ and call $(N C)$ options are given below:

$$
\begin{aligned}
& N P=h_{P} \times \operatorname{Max}\left[0,\left(f_{0}-f_{1}\right)\right] \times Q_{P}-h_{P} \times Q_{P} \times P P_{0}, \\
& N C=h_{C} \times \operatorname{Max}\left[0,\left(f_{1}-f_{0}\right)\right] \times Q_{C}-h_{C} \times Q_{C} \times C P_{0},
\end{aligned}
$$

where $P P_{0}$ and $C P_{0}$ represent put and call option premiums, respectively, $Q_{P}$ and $Q_{C}$ equal the total quantity hedged through put and call options, and $h_{P}\left(h_{C}\right)$ is the percentage of $Q_{P}\left(Q_{C}\right)$ that is hedged.

The end-of-period wealth, $W_{e}$, depends on net returns from holding RP policies and net returns from any put or call positions:

$$
W_{e}=W_{0}+N R_{B}+N P+N C .
$$

\subsection{Hedging By Combining Both SRA And Options}

The next scenario considered is where an insurance company would combine the use of options with reinsuring using the SRA. We assume the company transfers a certain percentage of its net losses in exchange for an equal percentage transfer of interest in premium in each state by assigning its policies to the commercial fund of the SRA. As per the provisions of the 2016 SRA, the company must retain at least a $35 \%$ interest in premium and potential net losses in each state, with the remainder ceded to the FCIC. Let ret represent the percent interest in premium and potential net losses that the insurer retains. We assume that the insurer retains the same percentage of the book of business in each state for simplicity.

The loss ratio is the total of indemnities paid divided by the total premiums for all RP policies. Mathematically, the loss ratio, LR as defined in equation (7), is

$$
L R=\frac{\sum_{i=1}^{m} \sum_{j=1}^{n}\left[I_{i j}\right]}{\sum_{i=1}^{m} \sum_{j=1}^{n}\left[P_{i j}\right]} .
$$

After accounting for the retention provision, the insurer's end-of-period wealth, $W_{e}$, is calculated as in (8). The amount of premiums, underwriting loss, and gain retained by the Commercial Fund company are calculated as described in the Appendix:

$$
W_{e}=W_{0}+\operatorname{ret}\left(N R_{B}+N P+N C\right) \text {. }
$$

\subsection{Utility Function}

Based on end-of-period wealth, a CRRA utility function is given by

$$
U\left(W_{e}\right)=\frac{W_{e}^{(1-R)}}{(1-R)} \text { for } R \neq 1,
$$




$$
U\left(W_{e}\right)=\ln W_{e} \text { for } R=1,
$$

where $R$ is the degree of relative risk aversion.

The objective function that maximizes the expected utility is expressed as

$$
\operatorname{Max}_{h_{P}, h_{C}} U\left(W_{e}\right)=\iint U\left(W_{e}\right) f\left(y_{i}, f_{i}\right) d y_{i} d f_{i} .
$$

The certainty equivalent $C E_{R}$ based on the above utility function is as follows:

$$
\begin{gathered}
C E_{R}=e^{U\left(W_{e}\right)} \text { if } R=1 \\
C E_{R}=\left[U\left(W_{e}\right)(1-R)\right]^{\frac{1}{1-R}} \text { if } R \neq 1 .
\end{gathered}
$$

As the crop insurer does not know the actual yield, we assume that the insurer is hedging a certain percentage of the value of one million bushels of corn using options. We conduct the grid search for hedging percentages that maximize the certainty equivalent, from 1 to $100 \%$ at every $0.5 \%$. The hedging percentage resulting in the highest certainty equivalent is deemed optimal.

\section{Data and Methods}

To estimate the optimal hedge ratios, the insurer's certainty equivalents are simulated over the period 1985-2019. The certainty equivalents are calculated in a sequentially refined grid search beginning with hedge ratios of $10 \%$, then $5 \%, 1 \%$, and one-half of $1 \%$ intervals. The hedge ratios resulting in the highest certainty equivalent are deemed optimal. We calculate the optimal hedge ratios in terms of the percentage of total insurance liability. ${ }^{4}$

First, we simulate each component of the insurer's book of business (i.e., indemnity, premium, and liability) for both RP and RP-HPE corn policies in three study regions: national level, the Corn Belt, ${ }^{5}$ and outside the Corn Belt. Indemnity, premium, and liability are functions of projected and harvest prices, the yield guarantee, and the actual yield. The technique used to simulate these components is explained below. We also simulate the net returns from the SRA based on the retention percentage and state-level loss ratios. This study considers three different levels for the company's share of the retained interest in premium and potential net losses: 35, 50, and 75\%. Finally, net returns from option positions are calculated at every defined hedge ratio interval.

\subsection{Calculating Representative Farm Yields}

To simulate the farm yields, we use the county yield data for corn from USDA's National Agricultural Statistics Service (NASS) and employ the yield variability model formulated by Coble, Dismukes, and Thomas (2007). Steps use to simulate farm yields are as follows:

1. A linear time trend is estimated using the regression function (15) for 265 counties in 31 states having a complete yield data series from 1985 to 2017:

$$
\widehat{y_{t i}}=b_{0}+b_{1} \times t_{i}
$$

where $\hat{y}, b_{0}$ and $b_{1}$ are the estimated values of the actual yield $y$ at time $t$ for the $i$ th farm, intercept, and the slope coefficient.

\footnotetext{
${ }^{4}$ Liability is the product of the 2019 projected price, coverage level and yield guarantee.

${ }^{5}$ The Corn Belt include five major corn production states: Illinois, Indiana, Iowa, Minnesota and Nebraska.
} 
2. Predicted yields for 2019 are computed using the estimated parameters of the linear trend regression. The 2019 predicted yield for each county is used as the approved yield for each representative farm.

3. We assume that the representative farm has a mean yield equal to the predicted county yield and the yield variability consistent with the average riskiness of farms participating in the corn RP insurance program (Coble, Dismukes, \& Thomas, 2007).

4. To calculate yield variability, first, we estimate the residuals from the linear time trend model used in step 1 . Then we search for a multiplier $(k)$ that will inflate county yield variability to a level consistent with RMA county base rates to depict the representative farms' yield accurately (Coble, Dismukes, \& Thomas, 2007):

$$
d_{f}=d_{c} * k
$$

where $d_{f}$ is farm yield deviation from expectation, $d_{c}$ is county yield deviation from expectation (i.e., the residuals), and $k$ is a multiplier or inflation factor that accounts the variability between the county and average farm yields (Coble, Dismukes, \& Thomas, 2007). Inflation factor is found out by conducting a grid search from 1 to 5 by interval of 0.2 that results in a variance that closely approximates the RMA county base rates.

5. These inflated residuals (also known as farm yield deviation) are then added to the 2019 predicted yields to generate detrended yields, which represent actual yields, for the representative farms.

\subsection{Future Price Calculation}

For simulating prices, we use the Commodity Research Bureau's (CRB) the national-level daily corn future prices from 1985 to 2018. Steps for simulating prices are as follows:

1. Following the approach used by RMA to set the projected price, the daily closing future prices for the December contract for corn are obtained for all trading days in February, and a mean value is computed.

2. Likewise, the harvest price is calculated as the mean price for all trading days in the month prior to the December contract expiration month. The simple difference between the harvest price and the projected price is the price change from planting to harvest time.

3. The historical harvest prices are then normalized to the 2019 price level using equation (16):

$$
f_{12019}=f_{0_{2019}}\left(\frac{f_{1 t}}{f_{0 t}}\right)
$$

that represents the product of the 2019 projected price $\left(f_{0_{2019}}\right)$ and the ratio of the historical harvest price $\left(f_{1 t}\right)$ to the historical projected price $\left(f_{0 t}\right)$ for each year.

\subsection{Indemnities, Premiums, and Liability Simulation}

After calculating yields and prices, we simulate the indemnity payment that reflects the amount by which revenue guarantee exceeds the actual revenue. Steps for simulating indemnity are given below:

1. Before calculating the revenue guarantee, we first calculate the acreage weighted average corn coverage level for RP in each county using the 2018 summary of RMA business data. 
2. Then, we estimate revenue guarantee for RP policies as a higher of projected or harvest price times approved yield times weighted average corn coverage level.

3. After estimating the revenue guarantee, actual revenue for RP policies is calculated as actual yields times harvest price.

4. Finally, the RP indemnities for each representative farm are calculated by subtracting actual revenue from the revenue guarantee.

While computing the indemnity's components (weighted average corn coverage level, revenue guarantee, and actual revenue) for each county representative farm, we draw yields and prices for every farm simultaneously to maintain the empirical price-yield correlation.

Steps for simulating premium and liability are as follows:

1. Actual premium is a function of various factors, such as price volatility, producer choice of coverage level, unit structure, crop rotation, and varying acreage over time. However, under the terms of the 1994 Crop Insurance Reform Act, the expected loss ratio of an insurance program must not be more than one indicating the projected amount of premiums at least equal indemnities. Thus, we simulate the actuarially fair premium for each representative farm to be equal to the yearly average of indemnities simulated for each farm.

2. The liability for each farm is calculated as the product of the 2019 projected price, weighted average corn coverage level, and 2019 predicted yield of each farm.

After calculating indemnities, premiums, and liabilities at farm levels, we aggregate total indemnities, premiums, and liabilities by year after weighting them with 2018 county net acreages giving more weights to counties with more acreages planted. Net acreage, as per RMA, is defined as the number of acres reported as being planted adjusted by the insured's share in the commodity. The aggregation by year further preserves the empirical correlation between prices and yields across space.

The aggregated total indemnity and premium are normalized using a ratio of 4.02 million dollars (maximum possible amount of liability, calculated as 2019 projected price times one million bushels, that could be incurred by the insurer) to liability. In other words, the premium received and indemnity paid by the insurance company represents certain percentages of the liability for insuring a million bushels of corn.

\subsection{Option Payout}

After simulating the company book of business's net return for every year, we compute option payout. If a crop insurer wants to protect against its exposure to both the upside and downside price risk of RP, as mentioned before, it must purchase some combination of put and call options.

The insurer knows the expected yields, but actual production is unknown. Therefore, we assume that the crop insurer is hedging a certain percentage of the value of one million bushels of corn using options. We conduct the grid search for hedging percentages that maximize the certainty equivalent, at every $0.5 \%$ for each year when put and call options are mixed (200 scenarios). In other words, for every year, we assume that the crop insurer could employ, for example, one of the following hedging strategies:

1) the combination of a put option hedging zero percent of one million bushels and the call options hedging from 0 to $100 \%$ by an increment of $0.5 \%$,

2) the combination of a put option hedging $0.5 \%$ of one million bushels and the calls hedging from 0 to $100 \%$ by an increment of $0.5 \%$,

3) the combination of a put option hedging $1 \%$ of one million bushels and the calls hedging from 0 to $100 \%$ by an increment of $0.5 \%$ so on. 
Thus, for every year, we have 40,401 combinations of put and call options. Each year's option payouts are calculated using (4) and (5) for put and call options, respectively. The put and call option premiums were calculated to be fair expected option premiums based on data from 1985 to 2017.

\subsection{Calculation of End-Of-Period Wealth, Expected Utility, and Certainty Equivalent}

After calculating the option payout, we compute the end-of period-wealth for every year and every combination of put and call options. The crop insurer's initial wealth, $W_{0}$, is assumed to be $4,020,000$ dollars, an amount equal to the value of the crop protected. When the SRA is not considered, as in (6), end-of-period wealth is a function of initial wealth, net return from the book of business, and net option return. When the SRA is combined with options, as in (8), the end-ofperiod wealth consists of initial wealth, and the net return on the retained book of business and net option return is adjusted by the retain percentage.

After computing the end-of-period wealth, we estimate the utility for the crop insurer using equations (9) and (10). We assign the value of 1,2, and 3 for $\mathrm{R}$ to represent low-, moderate-, and high-risk aversion. For each risk aversion category, we estimate the yearly average utility for a given combination of put and call options to obtain the expected utility.

We then calculate the certainty equivalents for different relative risk aversions based on the expected utility estimates based on the expected utility estimates (12) and (13). The certainty equivalent reflects the crop insurer increased welfare from risk reduction due to hedging. A given combination of put and call that result in the highest certainty equivalent is deemed optimal hedge ratios.

\subsection{Alternative Scenarios}

This study simulates six different scenarios for RP and expected utilities for each scenario. These scenarios are presented in Table A1 in the appendix. Each scenario is a combination of region and risk management tools. The study regions cover the Corn Belt, outside the Corn Belt, and the United States as a whole. The risk management tools include a mix of put and call options and a mix of put and call options and SRA.

Our analysis separated the Corn Belt from the whole United States, because in major production regions for corn, there is empirical evidence of a natural hedge between farm yields and aggregate prices (Bulut et al. 2011; Coble et al. 2004; Finger 2012). Both yield and price components of crop revenue are random variables that are subject to systematic risk. The price risk is perfectly correlated for crop revenue policies with the same parameters. Here, parameters refer to both projected and harvest prices which are derived from the future markets. Sometimes, yield risk is also systematic if a positive correlation exists between yields on nearby farms due to spatially correlated weather events or disease (Holly Wang \& Zhang 2003). Since an inverse relationship exists between price and yield in the Corn Belt, a decrease in production can be offset by an increase in price. Yet, despite the natural hedge between yield and price, large decreases in harvest price or yields can sometimes result in large aggregate indemnity payments (Bulut et al., 2011).

\section{Results and Discussion}

This section is divided into two main sections: a) summary statistics of simulated quantities, including prices, option premiums, yields, and the company's book of business and b) optimal hedge ratios under different scenarios. 
Table 1. Summary statistics of simulated variables

\begin{tabular}{|c|c|c|c|}
\hline Variable & Regions & Mean & Standard Deviation \\
\hline Projected Price $(\$)$ per bushels & - & 3.232 & 1.15 \\
\hline Harvest Price $(\$)$ per bushels & - & 3.062 & 1.31 \\
\hline \multicolumn{4}{|c|}{ Average Option Premium for one million bushels } \\
\hline Put Options (\$) & - & $349,612.12$ & $357,562.28$ \\
\hline Call Options (\$) & - & $179,903.03$ & 423031.23 \\
\hline \multirow[t]{3}{*}{ Farm Yield (bushels per acre) } & National & 147.90 & 45.23 \\
\hline & Outside Corn Belt & 142.86 & 44.65 \\
\hline & Corn Belt & 167.34 & 42.13 \\
\hline \multirow[t]{3}{*}{ Total Indemnity paid (\$) } & National & $225,895.17$ & $653,129.5$ \\
\hline & Outside Corn Belt & 228438.81 & 653359.03 \\
\hline & Corn Belt & $216,069.71$ & 652249.02 \\
\hline \multirow[t]{3}{*}{ Total Premium received (\$) } & National & $225,895.17$ & $146,378.65$ \\
\hline & Outside Corn Belt & 228438.81 & 153272.07 \\
\hline & Corn Belt & $216,069.71$ & 115480.12 \\
\hline
\end{tabular}

Table 2. Optimal Hedge Ratios for RP when considering the option market only for a relative risk aversion coefficient of 2

\begin{tabular}{lccc}
\hline Study Regions & National & Outside Corn Belt & Corn Belt \\
\hline End-of-period Wealth (\$) & $4,033,925.72$ & $4,021,404.64$ & $4,039,717.12$ \\
\hline Put Option Optimal Hedge Ratio (\%) & 13.5 & 10 & 14 \\
\hline Call Option Optimal Hedge Ratio (\%) & 74 & 37 & 100 \\
\hline Combined Optimal Quantity Hedged (bu.) & 875,000 & 470,000 & $1,140,000$ \\
\hline Combined Optimal liability hedged (\$) & $3,517,500$ & $1,889,400$ & $4,582,800$ \\
\hline Certainty Equivalents (\$) & $4,021,486.57$ & $4,015,451.45$ & $4,018,342.88$ \\
\hline
\end{tabular}

Note: Tables $\mathrm{A} 2$ and $\mathrm{A} 3$ in the appendix show the optimal hedge ratios with risk aversion equal to 1 and 3 .

\subsection{Summary Statistics}

Table 1 summarizes the simulated variables' means and their standard deviation. The means of projected and harvested future prices for the period 1985-2017 equal $\$ 3.232 / \mathrm{bu}$. and $\$ 3.062 / \mathrm{bu}$., respectively, and their standard errors are less than 1.5. Table 1 also provides information on the fair expected option premiums for put and call options which equal $\$ 349,612.12$ and $\$ 179,903.03$ with the standard errors of \$ 357,562.28 and \$423,031.23 when one million bushels of corn are hedged. The average simulated corn yields for the whole nation, outside the Corn Belt and the Corn Belt, equals 147.90, 142.86, and 167 bushels per acreage with standard deviation 45.23, 44.65 , and 42.13 .

Table 2 further suggests that the crop insurer would have to indemnify less when the policies are sold in the Corn Belt as compared to the other two study regions. This is obvious, as the prices are assumed to be the same in all three study regions, and yields are high in the Corn Belt. All things being equal, and the lower harvest price would result in less indemnity payment in the Corn Belt in comparison with the other two study regions. Premiums vary across years due to changes 


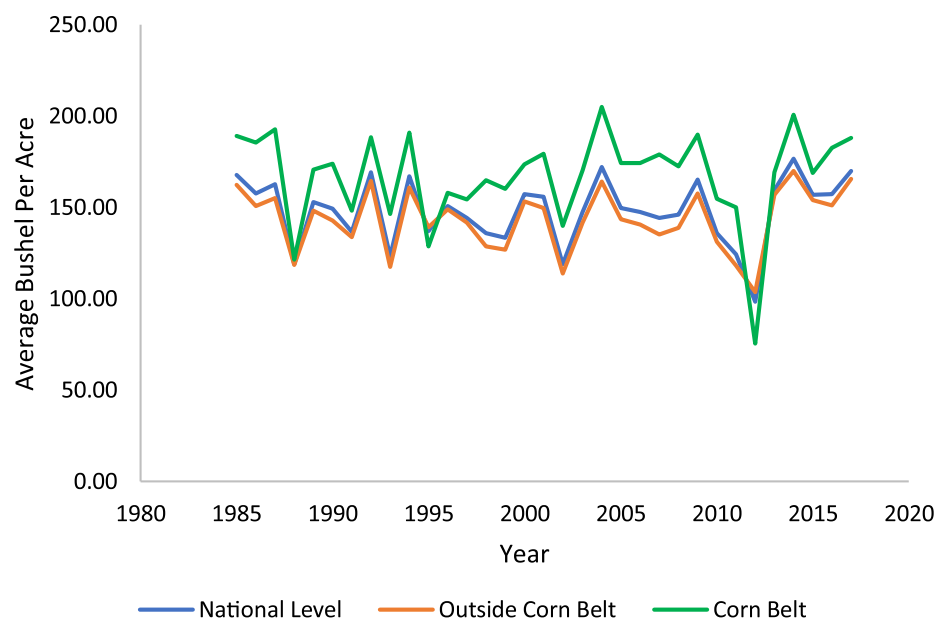

Figure 1. Detrended yields by year.

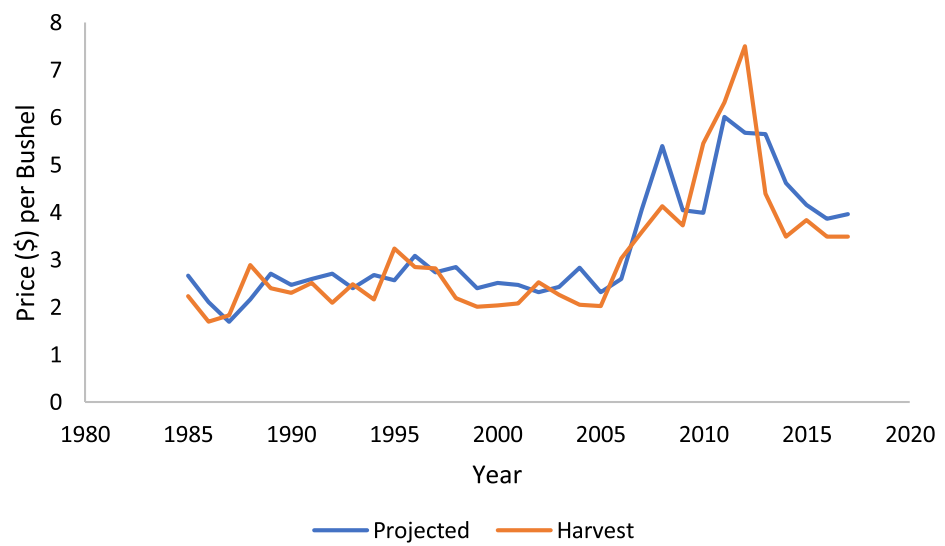

Figure 2. Simulated prices by year.

in price and liability. In all scenarios and all regions, mean premiums are equal to mean indemnities, as premium rates are set at an actuarially fair rate based on the simulated data.

Figure 1 depicts the simulated average yields for corn per acreage in the United States from 1985 to 2018. As you can see from this figure, the corn yield at each study region (i.e., national level, outside Corn Belt, and Corn Belt) shows a small decrease in yields from 1985 to 1990 and an increase in yields from 1991 onwards. However, in 2012, the yields for all three regions were significantly down. The 2012 simulated yields for all three regions are able to reflect the drought conditions in most of the corn-growing states that caused the corn production to decline rapidly.

Figure 2 represents the simulated price per bushels for corn over the periods, 1985-2018. The simulated data indicate that there were no appreciable changes in both prices until 2006 and then a steady increase in price until 2012 and a decrease in prices after 2012. Similarly, the projected prices seemed to be higher than the harvest prices until 2009, and after 2009, the harvest prices were higher until 2012, and after 2012, the projected prices were higher compared to the harvest prices.

Average simulated premiums and indemnities for each study region are shown in Figure 3. Figure 3 highlights that the average simulated premiums in all regions seem to be steady over the period. While individual premiums (as mentioned above) fluctuate across years due to changes 


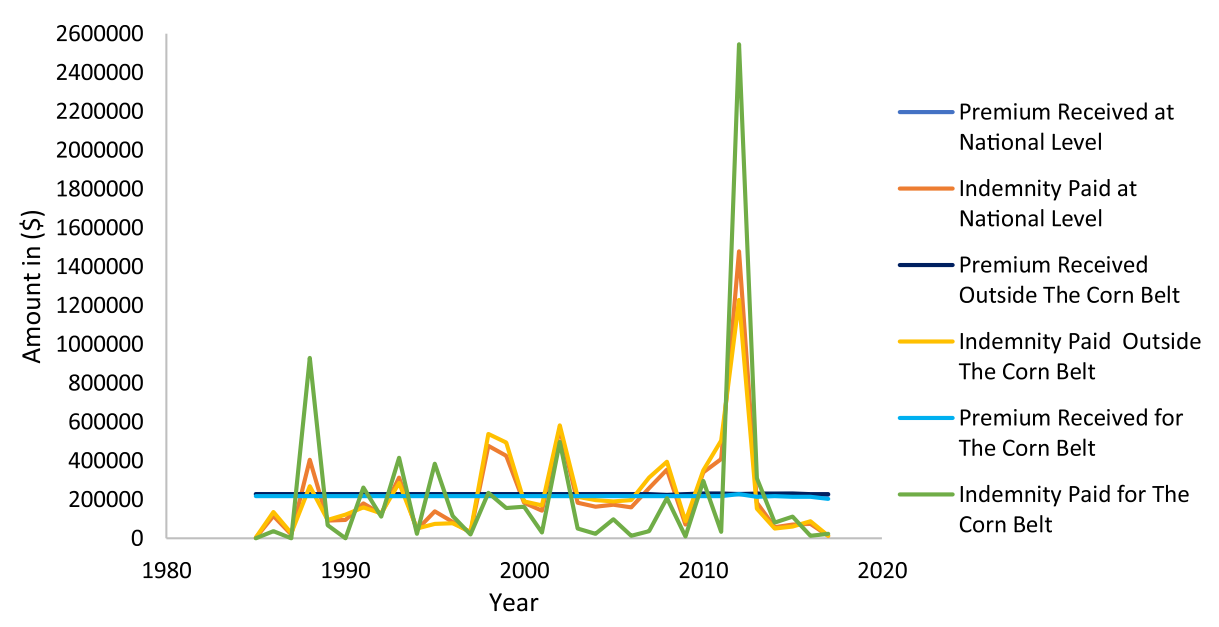

Figure 3. Simulated premiums and indemnities by year.

in price and liability, the average premium received for the Corn Belt is slightly lower as compared to the national level and outside the Corn Belt. The average premium received for the national level is slightly higher as compared to the outside Corn Belt. Average indemnities paid in all three regions are steady over time. However, in 2012, the decline in yields was much lower than the increase in harvest price triggering a huge amount of indemnity payments in all three study regions.

\subsection{Optimal Hedge Ratio Under Different Scenarios}

Table 3 presents optimal hedge ratios and certainty equivalents under different scenarios when the degree of risk aversion equals two. ${ }^{6}$ This study assumes that the crop insurer will buy a mix of both put and call options to hedge the price risk of corn RP policies. For RP policies, the lower harvest price results in the indemnity payment based on the projected price even if the actual yield is higher than the APH yield.

As per Table 3, the optimal put and call option hedge ratios are 13.5 and $74 \%$ for the whole United States, 10 and $37 \%$ for the study regions outside the Corn Belt, and 14 and $100 \%$ for the Corn Belt. Call options seem to be more efficient in hedging the upside price risk when yields decline. In the Corn belt, the simulation indicates that call options could hedge up to $100 \%$ of one million bushels when the yield declines, thus protecting the crop insurer from losses of the increased revenue guarantee. Whereas put options are inefficient in hedging, the downside price risk for RP policies sold in all three study regions, as the optimal hedge ratios are very low. Combined, both options hedge the optimal quantities of $875,000,470,000$, and 1,140,000 bushels and the optimal liabilities of $\$ 3,517,500, \$ 1,889,400$, and $\$ 4,582,800$ at the national level, outside the Corn Belt and the Corn Belt.

Tiwari (2017) had also examined whether the price risk of revenue policies could be hedged using options (i.e., put and call options separately) only. Her studies found quite a low optimal hedge ratio for both the options, thereby indicating the inefficiency of options to hedge the price risk of crop revenue policies. Furthermore, her assumption of hedging using put and call options separately instead of combinedly reflects insufficient hedging strategies that cannot provide complete coverage of price risk (i.e., both downside and upside price risk at the same time) to the

\footnotetext{
${ }^{6}$ The optimal hedge ratios with the degrees of risk aversion equal to one and three are shown in Tables A2 and A3 in the appendix.
} 
Table 3. Optimal Hedge Ratio for RP when mixing the options (Put \& Call) with SRA for a relative risk aversion coefficient of 2

\begin{tabular}{|c|c|c|c|c|c|c|c|c|c|}
\hline \multirow[b]{2}{*}{ Study Regions } & \multicolumn{3}{|c|}{ Retention Percent $=35 \%$} & \multicolumn{3}{|c|}{ Retention Percent $=50 \%$} & \multicolumn{3}{|c|}{ Retention Percent $=75 \%$} \\
\hline & $\begin{array}{c}\text { Combined } \\
\text { Optimal hedge } \\
\text { ratio }\end{array}$ & $\begin{array}{l}\text { End-of-period } \\
\text { Wealth }\end{array}$ & $\begin{array}{c}\text { Certainty } \\
\text { Equivalents } \\
\text { (\$) }\end{array}$ & $\begin{array}{c}\text { Combined } \\
\text { Optimal hedge } \\
\text { ratio }\end{array}$ & $\begin{array}{l}\text { End-of-period } \\
\text { Wealth }\end{array}$ & $\begin{array}{c}\text { Certainty } \\
\text { Equivalents } \\
\text { (\$) }\end{array}$ & $\begin{array}{c}\text { Combined } \\
\text { Optimal hedge } \\
\text { ratio }\end{array}$ & $\begin{array}{l}\text { End-of- } \\
\text { Period } \\
\text { Wealth }\end{array}$ & $\begin{array}{c}\text { Certainty } \\
\text { Equivalents } \\
(\$)\end{array}$ \\
\hline National & 0 & $4,072,613.92$ & $4,072,597.52$ & 0 & $4,095,162.75$ & $4,095,129.47$ & 0 & $4,132,744.13$ & $4,132,669.96$ \\
\hline Outside Corn Belt & 0 & $4,071,235.14$ & $4,071,223.96$ & 0 & $4,093,193.05$ & $4,093,170.36$ & 0 & $4,129,789.58$ & $4,129,738.94$ \\
\hline Corn Belt & 0 & $4,073,508.08$ & $4,073,479$ & 0 & $4,0964,40.12$ & $4,096,382.96$ & 0 & $4,134,660.18$ & $4,134,532.86$ \\
\hline
\end{tabular}

Note: Table A4 and A5 in the appendix show the optimal hedge ratios with risk aversion equal to 1 and 3. 
insurer. Furthermore, Driedger et al., (2016) found that the hedge positions (that is, long futures, and long call options) increased yield insurance losses as compared to unhedged positions. By contrast, in our case, call options are effective in hedging the upside price risk that triggers indemnity payment when yield declines in sufficient magnitude.

Our findings are consistent with the unique nature of crop revenue insurance. When crop prices decline between planting and harvest, RP functions as revenue insurance. The analysis further suggests that the put options can reduce some risk exposure of a crop insurer due to a price decrease. This implies that for a risk-averse crop insurer, the price risk reduction of RP by put options would provide greater expected utility as compared to the unhedged position, all else being equal. Furthermore, when the price increases between planting and harvest, RP functions as a yield insurance policy indemnified at the harvest price (because both the revenue guarantee and the realized revenue are increasing with the price). Results show that the risk of increased revenue guarantee due to the price increase and yield decline can be hedged using call options. Call options perform better than put options in transferring RP loss, thus indicating that options are better in hedging upside price risk than the downside price risk.

This study also analyzes the strategies where options are mixed with the SRA to determine whether the downside price risk of RP could be hedged efficiently. Table 4 reports the optimal hedge ratio under different scenarios when a crop insurer tries to hedge RP's price risk through the combination of options and the SRA. The combination of options and the SRA results in a zero optimal hedge ratio for each retention level for RP in all three regions. This suggests that the certainty equivalents for a crop insurer from the SRA alone at each retention level are higher than the combinations of SRA and options. The certainty equivalent from the SRA is higher, since the average end-of-period wealth from the SRA at each retention level is greater than the average endof-period wealth from the combinations of the SRA and options. Certainty equivalent is derived from the expected utility, which in turn, is the function of end-of-period wealth. When options are combined with the SRA, the crop insurer has to bear the additional fixed costs of buying options and exchange the premium based on the retention level for risk exposure that decreases the endof-period of wealth of the crop insurer.

Tables 3 and 4 further indicate that the average end-of-period wealth of a crop insurer from the SRA for each retention level is higher than the average end-of-period wealth when only options are used to hedge. This implies that a risk-averse crop insurer will prefer the SRA, which seems to guarantee the full protection against both price and yield risks in exchange for the premium, rather than the options where returns from hedge position are quite uncertain.

\section{Conclusion}

Insurance companies typically do not insure systematic risks. However, crop revenue insurance is one of the exceptions, as it offers a guarantee against highly systematic price risk. One way to hedge systematic risk is to utilize put and call option on future contracts. We examine whether an investment in options by a crop insurer, having a moderate degree of risk aversion, hedges the price risk inherent in RP. We find that a mix of put and call options could hedge the price risk of RP policies. Moreover, the effectiveness of options in hedging the price risk of corn RP depends on a positive correlation between the policy's indemnities and the returns from the options.

Call options can hedge the upside price risk of RP when yield declines. Put options, however, are not effective in hedging the downside price risk. This implies that the risk of increased liability due to upside price risk can be hedged using options better than downside price risk. Due to the inefficient offset of the downside price risk inherent in RP policies when options are used, this study also examines a strategy where we combined options with the SRA. We find that the optimal hedge ratio is zero, and option returns are negatively correlated with RP indemnities when the crop insurer mixed options and SRA to hedge the price risk, thereby indicating that USDA 
SRA is a clear substitute for options. Furthermore, the end-of-period wealth, on average, is higher when the crop insurer assigns RP policies to the Commercial Funds as per the SRA as compared to the end-of-period wealth when the crop insurer buys the options only to hedge the price risk. Thus, option purchasing provides no additional risk protection beyond what is provided by the SRA.

While this study has explored the possibility of mitigating price risks inherent in corn RP policies using put and call options, either alone or in combination with the SRA, future studies could consider a broader variety of hedging tools, such as swaps, futures, and forwards, or private reinsurance that might offer better solutions for mitigating the systematic underwriting risk such as price risk.

As call options were efficient in hedging the upside price risk of RP policies, our findings suggest that the crop insurer could hedge the upside price risk through the option market. The USDA could protect crop insurers only against the downside price risk. The possible extension of this work could be exploring what it would look like for USDA if the SRA does not cover the upside price risk of revenue insurance policies. This, in turn, will help USDA to decide to allocate resources dedicated to the upside price risk protection of revenue insurance policies to other programs.

Conflict of interests. Sweta Tiwari, Keith H. Coble, Barry J. Barnett, and Ardian Harri declare none.

Data availability statement. The authors confirm that the data supporting the study's findings are available within the research article.

\section{References}

Arrow, K.J. Essays in the Theory of Risk Bearing. Chicago: Markham Publishing Company, 1970.

Bulut, H., F. Schnapp, and K.J. Collins. "Systematic Risk and Crop Insurance in Retrospect and Prospect." Crop Insurance Today, November pp. 4-8, 2011.

BusinessWire. "Insights on the Global Reinsurance Providers Industry to 2030 Understand How the Market is Being Affected by COVID-19.” 2020. Internet site: https://www.businesswire.com/news/home/20200611005378/en/ Insights-on-the-Global-Reinsurance-Providers-Industry-to-2030-Understand-How-the-Market-is-Being-AffectedbyCOVID-19-ResearchAndMarkets.com (Accessed June 11, 2020).

Caldarelli, C.E. "The Dynamic Hedging Effectiveness for Soybean Farmers of Mato Grosso with Futures Contracts of BM\&F." Organizações Rurais \& Agroindustriais 12,1(2010):43-44.

Carlton, D.W. "Futures Markets: Their Purpose, Their History, Their Growth, Their Successes, and Failures." The Journal of Futures Markets 4,3(1984):237-71.

Cater, C.A. Futures and Options Markets. Long Grove, IL: Waveland Press Inc., 2003.

Coble, K.H., R. Dismukes, and J.W. Glauber. "Private Crop Insurers and the Reinsurance Fund Allocation Decision." American Journal of Agriculture Economics 89,3(2007):582-95.

Coble, K.H., R. Dismukes, and S. Thomas. "Policy Implications of Crop Yield and Revenue Variability at Differing Levels of Disaggregation.” Paper Presented at the AAEA Annual Meeting, Portland, Oregon, July 29-August 1, 2007.

Coble, K.H., R.G. Heifner, and M. Zuniga. "Implications of Crop Yield and Revenue Insurance for Producer Hedging." Journal of Agriculture and Resource Economics 25,2(2000):432-52.

Coble, K.H., J.C. Miller, M. Zuniga, and R. Heifner. "The Joint Effect of Government Crop Insurance and Loan Programs on the Demand for Futures Hedging." European Review of Agricultural Economics 31,3(2004):309-30.

Collins, B. "CARe-Crop Insurance Panel Discussion." 2011 Seminar on Reinsurance, Casualty Actuarial Society, 2011, pp.120. Internet site: https:/www.casact.org/education/reinsure/2011/handouts/C7-Collins.pdf (Accessed March 4, 2020).

Congress. Gov. "Federal Crop Insurance Reform and Department of Agriculture Reauthorization Act of 1994." 2020. Internet site: https://www.congress.gov/bill/103rd-congress/house-bill/4217/text (Accessed April 10, 2020).

Cox, S.H., and R.G. Schwebach. "Insurance Futures and Hedging Insurance Price Risk." Journal of Risk and Insurance 59, (1992):628-44.

Driedger, J., P. Lysa, and B. Milton. “The Potential to Use Futures and Options to Manage Crop Insurance Losses.” Paper Presented at AAEA annual meeting, Boston, MA, 31 July-2 August, 2016.

Duncan, J., and R.J. Myers. "Crop Insurance Under Catastrophic Risk." American Journal of Agricultural Economics 82,4(2000):842-55.

European Systemic Risk Board. Systemic Risks of Reinsurers. ESRB, 2015. Internet site: https://www.esrb.europa.eu/pub/pdf/ reports/2015-1216_esrb_report_annex_4.pdf (Accesssed December 15, 2020). 
Finger, R. "Effects of Crop Acreage and Aggregation Level on Price-yield Correlations." Agricultural Finance Review 72,3(2012):436-55. https://doi.org/10.1108/00021461211277277

Goodwin, B., and A. Hungerford. "Copula-Based Models of Systemic Risk in US Agriculture: Implications for Crop Insurance and Reinsurance Contracts.” American Journal of Agricultural Economics 97(2015):879-96.

Holly Wang, H., and H. Zhang. "On the possibility of a private crop insurance market: A spatial statistics approach." Journal of Risk and Insurance 70,1(2003):111-24.

International Association of Insurance Supervisors (IAIS). “Global Insurance Market Report.” 2012. Internet site: https:// www.iaisweb.org/page/supervisorymaterial/financial-stability/global-insurance-market-report-gimar/file/89238/2019-globalinsurance-market-report-gimar (Accessed December 12, 2020).

International Association of Insurance Supervisors (IAIS). "Global Insurance Market Report.” 2019. Internet Site: https:// www.iaisweb.org/page/supervisory-material/financial-stability/global-insurance-market-report-gimar/file/89238/2019-globalinsurance-market-report-gimar (Accessed April 10, 2021).

Jacobs, K.L., Z. Li, and D.J. Hayes. "Reference-dependent Hedging: Theory and Evidence from Iowa Corn Producers." American Journal of Agricultural Economics 100,5(2018):1450-68.

Kolb, R.W., and J.A. Overdahl. Financial Derivatives (Vol. 194). Hoboken, NJ: John Wiley \& Sons, 2003.

Lusk, J.L. "Distributional Effects of Crop Insurance Subsidies." Applied Economic Perspectives and Policy 39,1(2017):1-15.

Mahul, I., and Vermersch, D. "Hedging Crop Risk with Yield Insurance Futures and Options." European Review of Agricultural Economics 27,2(2000):109-26.

Mahul, O. "Hedging Price Risk in the Presence of Crop Yield and Revenue Insurance." European Review of Agricultural Economics 30,2(2003):217-39.

Miranda, M.J., and J.W. Glauber. "Systemic Risk, Reinsurance and the Failure of Crop Insurance Markets." American Journal of Agricultural Economics 79,1(1997):206-15.

Myers, R. J., and S.R. Thompson. "Generalized Optimal Hedge Ratio Estimation." American Journal of Agricultural Economics 71,4(1989):858-68.

NAIC. Derivatives. New York: NAIC of the Center for Insurance Policy and Research, 2018. Internet site: https://www.naic. org/cipr_topics/topic_derivatives.htm (Accessed August 17, 2019).

Niehaus, G., and S.V. Mann. "The Trading of Underwriting Risk: An Analysis of Insurance Futures Contracts and Reinsurance." Journal of Risk and Insurance 59,4(1992):601-27.

O'Donoghue, E. “The Effects of Premium Subsidies on Demand for Crop Insurance.” USDA-ERS Economic Research Report 169(2014):15-6.

Porth, L., K. Seng Tan, and C. Weng. “Optimal Reinsurance Analysis from A Crop Insurer's Perspective.” Agricultural Finance Review 73,2(2013):310-28.

Porth, L.M. "A Portfolio Optimization Model Combining Pooling and Group Buying of Reinsurance Under an Asset Liability Management Approach.” Journal of Risk and Insurance 82,3(2015):687-713.

Ramsey, A.F., Goodwin, B.K., and Ghosh, S.K. "How High the Hedge: Relationships between Prices and Yields in the Federal Crop Insurance Program." Journal of Agricultural and Resource Economics 44(2019):227-45.

Rosa, I. "Federal Crop Insurance: Program Overview for the 115th Congress." Report R45193, 2018.

Sévi, B. "On the Exact Minimum Variance Hedge of An Un-Certain Quantity With Flexibility." CREDEN (Centre de Recherche en Economie et Droit de l'Energie), 2004.

Shaik, S., K.H. Coble, T.O. Knight, A.E. Baquet, and G.F. Patrick. "Crop Revenue and Yield Insurance Demand: A Subjective Probability Approach.” Journal of Agricultural and Applied Economics 40(2008):757-66.

Shields, D.A. Renegotiation of the Standard Reinsurance Agreement (SRA) for Federal Crop Insurance. Washington, DC: Congressional Research Service, 40966, 2010.

Takao, A., and I. Lantara. “The Determinants of The Use of Derivatives in Japanese Insurance Companies." Society for Social Management System Internet Journal 6,1(2010):57-81.

Tiwari, S. "Hedging the Price Risk of Crop Revenue Insurance through the Options Market." Master's Thesis, Mississippi State University, 2017. Internet site: https://ir.library.msstate.edu/handle/11668/19956?show=full (Accessed December 15, 2020).

USDA-National Agricultural Statistics Services. Quick Stats: the US and All States County Corn Yield Data. Washington, DC, 2016. Internet site: https://www.nass.usda.gov/Quick_Stats (Accessed March 7, 2016).

USDA's RMA. “Federal Crop Insurance Corp: Summary of Business Report for 2018 thru 2021.” 2021. Internet site: https:// www3.rma.usda.gov/apps/sob/current_week/sobrpt2018-2021.pdf (Accessed March 28, 2021).

USDA Risk Management Agency. Summary of Business. Federal Crop Insurance Corporation. 2016. Internet site: http:// prodwebnlb.rma.usda.gov/apps/SummaryofBusiness/ReportGenerator (Accessed March 5, 2016).

USDA. Standard Reinsurance Agreement. Washington DC: U.S. Department of Agriculture- Risk Management Agency, 2015.

US Department of Agriculture- Risk Management Agency. Standard Reinsurance Agreement. 2019. Internet site: https:// www.rma.usda.gov/pubs/ra/sraarchives/16sra.pdf (Accessed January 5, 2019).

Vedenov, D.V, M.J. Miranda, R. Dismukes, and J.W. Glauber. "Economic Analysis of The Standard Reinsurance Agreement." Agricultural Finance Review 64,2(2004):119-34. https://doi.org/10.1108/00214660480001158 
Walters, C., and R. Preston. "Net Income Risk, Crop Insurance and Hedging." Agricultural Finance Review 78,1(2018):135-51. https://doi.org/10.1108/AFR-05-2017-0036

Wang, H.H., L.D. Makus, and X. Chen. "The Impact of US Commodity Programs on Hedging in The Presence of Crop Insurance." European Review of Agricultural Economics 31,3(2004):331-52.

Witt, H.J., T.C. Schroeder, and M.L. Hayenga. "Comparison of Analytical Approaches for Estimating Hedge Ratios for Agricultural Commodities.” Journal of Futures Markets 7,2(1987):135-46.

Wong, M. Capital Markets Bureau Primer: Derivatives. New York: NAIC \& CIPR, 2018. Internet site: https://www.naic.org/ capital_markets_archive/primer_180626.pdf (Accessed August 16, 2019).

Ye, M., R. Wang, G. Tuo, and T. Wang. "Crop Price Insurance in China: Pricing and Hedging Using Futures Market." China Agricultural Economic Review 9,4(2017):567-87. https://doi.org/10.1108/CAER-12-2015-0178

\section{Appendix. A Calculation of Underwriting Loss and Gain as per SRA}

The amount of underwriting loss retained by the insurer for the Commercial Fund is calculated as follows:

\section{Underwriting Loss}

i. When the company's loss ratio exceeds $100 \%$ and is less than or equal to $160 \%, L_{r}>1$ and $L_{r} \leq 1.6$, then the retention amount for underwriting loss, $\mathrm{I}_{r_{i j}}$ is calculated as

$$
\begin{gathered}
I_{r_{i}}=P_{r_{i j}} \times\left(L_{r}-1\right) \times 0.65 \text { State Group 1, and } \\
I_{r_{i j}}=P_{r_{i j}} \times\left(L_{r}-1\right) \times 0.425 \text { State Group } 2 \text { and 3, }
\end{gathered}
$$

where $x$ is the retention percent, and $P_{r_{i j}}=x \times P_{i j}$ is the retention premium.

where $\mathrm{x}$ is the retention percent, and $P_{r_{i j}}=x \times P_{i j}$ is the retention premium.

According to USDA (2015), "State Group 1" includes Illinois, Indiana, Iowa, Minnesota, and Nebraska, and "State Groups 2 and 3" include the rest of the states.

ii. When the company's loss ratio exceeds $160 \%$ and is less than or equal to $220 \%, L_{r}>1.60$ and $L_{r} \leq 2.20$, then the retention amount for underwriting loss, $\mathrm{I}_{r_{i j}}$ is calculated as

$$
\begin{gathered}
I_{r_{i j}}=P_{r_{i j}} \times(1.60-1) \times 0.65+P_{r_{i j}}\left(L_{r}-1.60\right) \times 0.45 \text { State Group } 1, \\
I_{r_{i j}}=P_{r_{i j}} \times(1.60-1) \times 0.425+P_{r_{i j}}\left(L_{r}-1.60\right) \times 0.20 \text { State Group } 2 \text { and } 3 .
\end{gathered}
$$

iii. When the company's loss ratio exceeds $220 \%$ and is less than or equal to $500 \%, L_{r}>2.20$ and $L_{r} \leq 5.0$, then the retention amount for underwriting loss, $\mathrm{I}_{r_{i j}}$ is calculated as

$$
\begin{gathered}
I_{r_{i j}}=P_{r_{i j}} \times(1.60-1) \times 0.65+P_{r_{i j}}(2.20-1.60) \times 0.45+P_{r_{i j}}\left(L_{r}-2.20\right) \times 0.10 \text { State Group 1, } \\
I_{r_{i j}}=P_{r_{i j}} \times(1.60-1) \times 0.425+P_{r_{i j}} \times(2.20-1.60) \times 0.20+\left(L_{r}-2.20\right) \times 0.05 \quad \text { State Group } 2 \text { and } 3 .
\end{gathered}
$$

iv. When the company's loss ratio exceeds $500 \%, L_{r}>5.0$, then the retention underwriting loss, $\mathrm{I}_{r_{i j}}$ is calculated as

$$
\begin{aligned}
I_{r_{i j}}= & P_{r_{i j}} \times(1.60-1) \times 0.65+P_{r_{i j}}(2.20-1.60) \times 0.45+P_{r_{i j}}(5.0-2.20) \times 0.10 \\
& +P_{r_{i j}}\left(L_{r}-5.0\right) \times 0 \text { State Group } 1, \\
I_{r_{i j}}= & P_{r_{i j}} \times(1.60-1) \times 0.425+P_{r_{i j}} \times(2.20-1.60) \times 0.20+P_{r_{i j}}(5.0-2.20) \times 0.05 \\
& +P_{r_{i j}}\left(L_{r}-5.0\right) \times 0 \text { State Group } 2 \text { and } 3 .
\end{aligned}
$$

\section{Underwriting Gains}

i. When the company's loss ratio is less than or equal to $100 \%$ but greater than or equal to $65 \%$, $L_{r} \leq 1$ and $L_{r} \geq 0.65$, then the retention amount for underwriting gain, $\mathrm{I}_{r_{i j}}$ is calculated as

$$
I_{r_{i j}}=P_{r_{i j}} \times\left(1-L_{r}\right) \times 0.75 \text { State Group } 1 \text {, }
$$




$$
I_{r_{i j}}=P_{r_{i j}} \times\left(1-L_{r}\right) \times 0.975 \text { State Group } 2 \text { and } 3 .
$$

ii. When the company's loss ratio is less than $65 \%$ but is greater than or equal to $50 \%, L_{r}<0.65$ and $L_{r} \geq 0.5$, then the retention amount for underwriting gain, $\mathrm{I}_{r_{i j}}$ is calculated as

$$
\begin{gathered}
I_{r_{i j}}=P_{r_{i j}} \times(1-0.65) \times 0.75+P_{r_{i j}}\left(0.65-L_{r}\right) \times 0.40 \text { State Group } 1, \\
I_{r_{i j}}=P_{r_{i j}} \times(1-0.65) \times 0.975+P_{r_{i j}}\left(0.65-L_{r}\right) \times 0.40 \text { State Group } 2 \text { and } 3 .
\end{gathered}
$$

iii. When the company's loss ratio is less than $50 \%, L_{r}<0.5$, then the retention amount for underwriting gain, $\mathrm{I}_{r_{i j}}$ is calculated as

$$
\begin{gathered}
I_{r_{i j}}=P_{r_{i j}} \times(1-0.65) \times 0.75+P_{r_{i j}}(0.65-0.5) \times 0.40+P_{r_{i j}}\left(0.5-L_{r}\right) \times 0.05 \text { State Group 1, } \\
I_{r_{i j}}=P_{r_{i j}} \times(1-0.65) \times 0.975+P_{r_{i j}} \times(0.65-0.5) \times 0.40+\left(0.5-L_{r}\right) \times 0.05 \text { State Group } 2 \text { and } 3 .
\end{gathered}
$$

Table A1. Different scenarios considered in simulations for RP

\begin{tabular}{lll}
\hline Regions & Options & Mix of Options and SRA \\
\hline National & Put \& Call, National & Put \& Call, SRA, National \\
\hline Outside Corn Belt & Put \& Call, Outside Corn Belt & Put \& Call, SRA, Outside Corn Belt \\
\hline Corn Belt & Put \& Call, Corn Belt & Put \& Call, SRA, Corn Belt \\
\hline
\end{tabular}

Table A2. Optimal Hedge Ratios when considering the option market only for a relative risk aversion coefficient of 1

\begin{tabular}{lccc}
\hline Study Regions & National & Outside Corn Belt & Corn Belt \\
\hline Put Option Optimal Hedge Ratio (\%) & 13 & 9.5 & 15 \\
\hline Call Option Optimal Hedge Ratio (\%) & 70.5 & 36 & 97 \\
\hline Combined Optimal Quantity Hedged (bu.) & 835,000 & 455,000 & $1,120,000$ \\
\hline Combined Optimal liability hedged $(\$)$ & $3,356,700$ & $1,829,100$ & $4,502,400$ \\
\hline Certainty Equivalents $(\$)$ & $4,027,630.95$ & $4,018,440.41$ & $4,028,746.60$ \\
\hline
\end{tabular}

Table A3. Optimal Hedge Ratios when considering the option market only for a relative risk aversion coefficient of 3

\begin{tabular}{lccc}
\hline Study Regions & National & Outside Corn Belt & Corn Belt \\
\hline Put Option Optimal Hedge Ratio (\%) & 13.5 & 10 & 11.5 \\
\hline Call Option Optimal Hedge Ratio (\%) & 76.5 & 37.5 & 100 \\
\hline Combined Optimal Quantity Hedged (bu.) & 900,000 & 475,000 & $1,115,000$ \\
\hline Combined Optimal liability hedged (\$) & $3,618,000$ & $1,909,500$ & $4,482,300$ \\
\hline Certainty Equivalents (\$) & $4,015,574.43$ & $4,012,444.83$ & $4,008,421.74$ \\
\hline
\end{tabular}


Table A4. Optimal Hedge Ratios for RP when mixing the options (Puts \& Call) and SRA for a relative risk aversion coefficient of 1

\begin{tabular}{|c|c|c|c|c|c|c|}
\hline \multirow[b]{2}{*}{ Study Regions } & \multicolumn{2}{|c|}{ Retention Percent = $35 \%$} & \multicolumn{2}{|c|}{ Retention Percent $=50 \%$} & \multicolumn{2}{|c|}{ Retention Percent $=75 \%$} \\
\hline & $\begin{array}{c}\text { Combined } \\
\text { Optimal hedge } \\
\text { ratio }\end{array}$ & $\begin{array}{c}\text { Certainty } \\
\text { Equivalents } \\
(\$)\end{array}$ & $\begin{array}{c}\text { Combined } \\
\text { Optimal hedge } \\
\text { ratio }\end{array}$ & $\begin{array}{c}\text { Certainty } \\
\text { Equivalents } \\
(\$)\end{array}$ & $\begin{array}{c}\text { Combined } \\
\text { Optimal hedge } \\
\text { ratio }\end{array}$ & $\begin{array}{c}\text { Certainty } \\
\text { Equivalents } \\
\text { (\$) }\end{array}$ \\
\hline National & 0 & $4,072,605.72$ & 0 & $4,095,146.10$ & 0 & $4,132,707.02$ \\
\hline $\begin{array}{l}\text { Outside Corn } \\
\text { Belt }\end{array}$ & 0 & $4,071,229.55$ & 0 & $4,093,181.71$ & 0 & $4,129,764.28$ \\
\hline Corn Belt & 0 & $4,073,493.99$ & 0 & $4,096,411.52$ & 0 & $4,134,569.47$ \\
\hline
\end{tabular}

Table A5. Optimal Hedge Ratios for RP when mixing the options and SRA for a relative risk aversion coefficient of 3

\begin{tabular}{|c|c|c|c|c|c|c|}
\hline \multirow[b]{2}{*}{ Study Regions } & \multicolumn{2}{|c|}{ Retention Percent $=35 \%$} & \multicolumn{2}{|c|}{ Retention Percent $=50 \%$} & \multicolumn{2}{|c|}{ Retention Percent $=75 \%$} \\
\hline & $\begin{array}{c}\text { Combined } \\
\text { Optimal hedge } \\
\text { ratio }\end{array}$ & $\begin{array}{c}\text { Certainty } \\
\text { Equivalents } \\
\text { (\$) }\end{array}$ & $\begin{array}{c}\text { Combined } \\
\text { Optimal hedge } \\
\text { ratio }\end{array}$ & $\begin{array}{c}\text { Certainty } \\
\text { Equivalents } \\
\text { (\$) }\end{array}$ & $\begin{array}{c}\text { Combined } \\
\text { Optimal hedge } \\
\text { ratio }\end{array}$ & $\begin{array}{c}\text { Certainty } \\
\text { Equivalents } \\
\text { (\$) }\end{array}$ \\
\hline National & 0 & $4,071,229.55$ & 0 & $4,095,112.84$ & 0 & $4,132,669.96$ \\
\hline $\begin{array}{l}\text { Outside Corn } \\
\text { Belt }\end{array}$ & 0 & $4,071,218.37$ & 0 & $4,093,159$ & 0 & $4,129,713.56$ \\
\hline Corn Belt & 0 & $4,073,465.83$ & 0 & $4,096,354.43$ & 0 & $4,134,469.35$ \\
\hline
\end{tabular}

Cite this article: Tiwari, S., K.H. Coble, B.J. Barnett, and A. Harri. Hedging the Price Risk Inherent in Revenue Protection Insurance. Journal of Agricultural and Applied Economics (2021), 53, 510-530. https://doi.org/10.1017/aae.2021.20 